\title{
A Study of Serum Iron Profile in Patients with Chronic Kidney Disease
}

\author{
Indira Shastry ${ }^{1}$ and Sushma Bekurkar ${ }^{2 *}$ \\ ${ }^{1}$ Department of Pathology, American University of Antigua College of Medicine, West Indies \\ ${ }^{2}$ Department of Pathology, Kasturba Medical College, Manipal Academy of Higher Education, Manipal, Karnataka, India.
}

\section{ABSTRACT}

Background: Even though anemia and iron deficiency can increase the morbidity and mortality in patients with chronic kidney disease (CKD), an iron overload can be dangerous as well.

Aim: Identify the number of CKD patients with iron deficiency, iron overload, acute phase reaction and anemia of chronic disease in a tertiary care hospital.

Material and Methods: The study was conducted in Kasturba medical college, Manipal. 154 patients with CKD were selected for the study irrespective of their treatment status with hematinics and/or erythropoietin.

Results: The mean total serum iron levelswere $61 \mu \mathrm{g} / \mathrm{dl}$, Total Iron Binding Capacity (TIBC) $216.43 \mu \mathrm{g} / \mathrm{dl}$, serum ferritin $539.68 \mu \mathrm{g} / \mathrm{dl}$, and transferrin saturation of $32.18 \%$ respectively. When the serum iron profile of individuals was analyzed, majority (54.25\%) of the patients were found to have acute phase reaction and most of them were in advanced stage of renal failure. Normal serum iron profile was found in $37.2 \%$ patients, iron overload in $2.2 \%$, anemia of chronic disease in $5.3 \%$ and iron deficiency in $1 \%$ cases. These findings were statistically significant with the $\mathrm{P}$ value of 0.001 .

Conclusion: Most common type of serum iron profile found in the study population was acute phase reaction (54\%) and majority of them were in stage 5 renal failure. Hence, before beginning an iron therapy, all the patients with anemia in chronic kidney disease should be evaluated for body iron status to prevent iron overload.

Keywords: Chronic Kidney Disease, Serum Iron, TIBC,Ferritin.

\section{Introduction}

Chronic kidney disease (CKD) has gained a profound importance because of morbidity and mortality, not only because of disease itself, but also because of complications associated with the disease. Anemia is an important complication which can be multi factorial and can have diverse etiology in CKD.

Iron deficiency in patients with chronic kidney failure can be absolute, because of blood loss during hemodialysis or gastro intestinal bleeding in non-hemodialysis patients ${ }^{3,4}$. The second form of iron deficiency is a functional type, due to sequestration of iron in reticuloendothelial system primarily due to inflammation. This leads to an iron deficient erythropoiesis in spite of normal iron stores. This state of iron deficient erythropoiesis when seen in chronic diseases is called anemia of chronic disease ${ }^{5}$.

Diagnosis of absolute iron deficiency is based on Serum ferritin levels, which is an indicator of total body iron stores. Low serum ferritin levels indicative of low body iron stores, high total iron binding capacity and reduced total serum iron levels are indicative of absolute iron deficiency. In cases of functional iron deficiency in anemia of chronic disease, the serum ferritin levels can be normal, with low total iron binding capacity and low serum iron levels. In acute phase response the serum iron levels and TIBC are low, and serum ferritin is usually elevated. In case of iron overload, serum iron and serum ferritin are elevated, and TIBC can be normal or low ${ }^{6,7}$.

Iron overload is a condition with increased total body iron, that can be associated with time dependent organ impairment. Intracellular iron accumulation can cause cell damage and increased oxidative stress. Based on the study done in the patients with hereditary hemochromatosis and transfusion induced overload, a combination of high serum ferritin and high transferrin saturation is of a particular concern ${ }^{8,9}$.

In the present study, we tried to identify the total number of patients with iron deficiency anemia, anemia of chronic disease, and iron overload in chronic kidney disease patients who are being treated at Kasturba medical college and hospital, Manipal, Udupi, Karnataka, India.

\section{Materials and Method}

Total of 154 patients diagnosed with chronic kidney disease with available serum iron studies were selected. These 
patients were randomly selected irrespective of treatment status with hematinics or erythropoietin. The study was of ambispective type. The study was conducted in Kasturba hospital Manipal, Udupi from the period of Nov 2011 till June 014 . None of the patients were involved directly in the study. The lab results and patient information was retrieved from hospital information system and research population data. Institutional ethical clearance was taken.

Study population was divided into five groups, depending on the stage of renal failure.

Stage of renal failure was determined by measuring eGFR, by using the formula $=175 \times$ standardized Scr $^{-1.154} \times$ age $^{-0.203}$

Estimation of total serum iron, serum ferritin, and TIBC were done by using Cobas 6000 . The study population was divided into three groups, which had the serum levels of above mentioned tests in the range of below normal, normal and above normal values.

Transferrin saturation was calculated as (serum iron/ TIBC)* $100^{10}$. Study population was divided into three groups as $<20 \%, 20-50 \%$ and $>50 \%$.

Patients were categorized with the help of total serum iron, TIBC, serum ferritin and transferrin saturation into, normal serum profile, anemia of chronic disease, iron deficiency, iron overload and acute phase reaction ${ }^{10}$.

Statistical analysis was done by using SPSS 20 and data analysis was done by using Spearman's rho correlation and $\mathrm{P}$-value of $<0.05$ was considered significant.

\section{Results}

The age distribution of the study population ranged from 18 yrs to 82 yrs with the mean of $52 \pm 14$ yrs, majority of patients were between 51-70 yrs of age. Diabetes was the leading cause of CKD (38.3\%) followed by obstructive uropathy $(10.3 \%)$ and hypertension $(7.3 \%)$.

Total serum iron ranged from $12-190 \mu \mathrm{g} / \mathrm{dl}$, with a mean of $61 \mu \mathrm{g} / \mathrm{dl}$. Decreased total serum iron was found in 62 cases $(40.2 \%)$ and an increased serum iron in 2 cases $(1.29 \%)$. Spearman's rho correlation co-efficient was 0.065 and interpreted to have a very weak positive relationship with the stage of renal failure, with a P value of 0.423 (Table-1).

The Total Iron Binding Capacity (TIBC) ranged from 60$531 \mu \mathrm{g} / \mathrm{dl}$, with a mean of $216.43 \mu \mathrm{g} / \mathrm{dl}$. Decrease in TIBC was found in 63 cases $(40.9 \%)$ and an increase in TIBC found in 3 cases $(1.94 \%)$. Spearman's rho correlation coefficient for TIBC when compared with stage of renal failure was -0.167 , a weak negative relationship and a $\mathrm{P}$ value of 0.039 (Table-1)

Serum Ferritin ranged from 5 - >2269.0 ng/dl, with a mean of $539.68 \mathrm{ng} / \mathrm{dl}$. An increased serum ferritin was observed in 82 cases $(53.24 \%)$ and a decrease in serum ferritin in 2 cases (1.29\%). Spearman's rho correlation co-efficient for serum ferritin was 0.288 with a weak positive relation with stage of renal failure and P value of 0.00 (Table-1).

Transferrin saturation ranged from $3.16-92.5 \%$, with a mean of $30.5 \%$. Increase in transferrin saturation was observed in 26 cases $(16.8 \%)$ and a decrease was observed in 57 cases $(37 \%)$. Spearman correlation co-efficient was 0.176 and it was interpreted to have a weak positive relationship with stage of renal failure and a P value of 0.029 .

No significant relationship was found when the degree of anemia was compared with total serum iron, TIBC, serum ferritin, and transferrin saturation.

When the status of total serum iron was correlated with transferrin saturation levels, a strong positive relationship was found (correlation coefficient of 0.672 ) and it was statistically significant with a $P$ value of 0.000 . Twenty-four patients with normal total serum iron levels had elevated transferrin saturation levels, this can be explained since many patients had TIBC levels in a low normal range. Relationship between TIBC and transferrin saturation found be weak negative (correlation coefficient of -0.180) and it was statistically significant with a $P$ value of 0.026 . A correlation between serum ferritin and transferrin saturation found to be of moderately positive strength (correlation coefficient 0.325 ) with a significant $P$ value 0.000 (table-2).

Among 26 patients with increased transferrin saturation, 22 of them had increased serum ferritin levels. In 57 patients with decreased serum transferrin saturation, only two had decreased serum ferritin and 47 had decreased total serum iron (table-2).

With the above observation, correlation between transferrin saturation and serum ferritin was found to be more useful in determining body iron status than transferrin saturation alone.

Since the study was not funded, the additional tests required to interpret the serum iron studies could not be performed and, the therapeutic status with erythropoietin and other drugs were not available for many of the patients. Hence amongst 154 patients, a confirmed interpretation could be done for 94 cases.

We found $35(37.2 \%)$ patients had normal serum iron profile, 1 (1\%) had features of iron deficiency, 51 (54.25\%) cases had features suggestive of acute phase response, $5(5.31 \%)$ patients had anemia of chronic disease and 2 $(2.2 \%)$ showed iron overload. A significant moderate positive relationship (correlation coefficient of 0.345 ) was found with a $\mathrm{P}$ value of 0.001 .

The peripheral smear was reviewed for these patients and it was correlated with serum iron profile. Upon the review, 
majority of patients had normocytic normochromic blood picture and 10 patients were found to have microscopic hypochromic blood picture. Among these patients with microcytic hypochromic blood picture, 5/10 patients had serum iron profile suggestive of anemia of chronic disease, $1 / 10$ had iron deficiency, and 3/10 had features suggestive of acute phase reaction. Data was not available for one patient.

\section{Discussion}

Total serum iron in the present study was in accordance with the study by Talwar et al ${ }^{11}$ (table-4), but in the current study the high mean serum ferritin values was due to inflammatory state in majority of individuals. The majority of study population $(65 \%)$ in the Talwar et al study had microcytic hypochromic anemia because of iron deficiency and 33\% patients had parasitic infestation. Majority of the study population in our study had normocytic normochromic blood picture and iron deficiency was seen in few.

Study by Singh et al ${ }^{12}$ (table-4) showed higher mean values for Serum iron and lower serum ferritin levels than our study. This is because in Singh et al study, patients had received erythropoietin therapy and fall in serum ferritin in the cases indicate iron utilization by replicating erythroid cells. In our study, few patients had received erythropoietin, therefore no significant decrease in mean serum ferritin levels was observed.

In 2010 Jairam et al ${ }^{13}$ (table-4) revealed that $60 \%$ of the End Stage Renal Disease (ESRD) patients in his their study had adequate iron stores because most of them had received parenteral iron therapy before presentation to the hospital, and iron deficiency was seen in patients with no parenteral or oral iron. A wide use of parenteral iron and repeated transfusions in cases of CKD has led to an iron overload. $\mathrm{He}$ also concluded that the use of serum ferritin alone for defining iron overload is faulty, because 2-3-fold elevations in ferritin (acute phase reactant) levels with inflammatory activation is known, which is common in CKD patients.

In the study by Deori et al ${ }^{14}$ in 2016 (table-4), $26 \%$ of patients had absolute iron deficiency, and it was the most common cause of anemia. In the present study majority of the patients had serum iron profile suggestive of acute

Table 1: Correlation of total serum iron, TIBC, serum ferritin and transferrin saturation (normal value is given in parenthesis) with the stage of renal failure $(n=154)$.

\begin{tabular}{|c|c|c|c|c|c|c|c|c|c|c|c|c|}
\hline \multirow{2}{*}{$\begin{array}{l}\text { Stage } \\
\text { of renal } \\
\text { failure }\end{array}$} & \multicolumn{3}{|c|}{$\begin{array}{l}\text { Total serum iron } \\
\text { (45-170 microg/dl) }\end{array}$} & \multicolumn{3}{|c|}{$\begin{array}{c}\text { TIBC } \\
(200-430 \mathrm{microg} / \mathrm{dL})\end{array}$} & \multicolumn{3}{|c|}{$\begin{array}{l}\text { Serum Ferrtin } \\
(23.9-336 \mathrm{ng} / \mathrm{dL})\end{array}$} & \multicolumn{3}{|c|}{$\begin{array}{c}\text { Transferrin saturation } \\
(20-50 \%)\end{array}$} \\
\hline & $<45$ & $45-170$ & $>170$ & $<200$ & $200-430$ & $>430$ & $<23.9$ & 23.9-336 & $>336$ & $<20$ & $20-50$ & $>50$ \\
\hline 3 & 3 & 5 & 0 & 2 & 4 & 2 & 0 & 6 & 2 & 5 & 2 & 1 \\
\hline 4 & 16 & 18 & 0 & 11 & 22 & 1 & 2 & 21 & 11 & 15 & 17 & 2 \\
\hline 5 & 43 & 67 & 2 & 50 & 62 & 0 & 0 & 43 & 69 & 37 & 52 & 23 \\
\hline
\end{tabular}

Table 2: Correlation of total serum iron, TIBC and serum ferritin (normal value is given in parenthesis) with transferrin saturation $(n=154)$.

\begin{tabular}{|c|c|c|c|c|c|c|c|c|c|}
\hline \multirow{2}{*}{$\begin{array}{c}\text { Transferrin } \\
\text { saturation } \\
(20-50 \%)\end{array}$} & \multicolumn{3}{|c|}{$\begin{array}{l}\text { Total serum iron } \\
\text { (45-170 microg/dl) }\end{array}$} & \multicolumn{3}{|c|}{ TIBC (200-430microg/dL) } & \multicolumn{3}{|c|}{ Serum Ferrtin (23.9-336 ng/dL) } \\
\hline & $<45$ & $45-170$ & $>170$ & $<200$ & $200-430$ & $>430$ & $<23.9$ & $23.9-336$ & $>336$ \\
\hline$<20 \%$ & 47 & 10 & 0 & 19 & 35 & 3 & 2 & 34 & 21 \\
\hline $20-50 \%$ & 15 & 56 & 0 & 29 & 42 & 0 & 0 & 32 & 39 \\
\hline$>50 \%$ & 0 & 24 & 2 & 15 & 11 & 0 & 0 & 4 & 22 \\
\hline
\end{tabular}

Table 3: Correlation of serum iron profile with stage of renal failure $(n=94)$.

\begin{tabular}{|c|c|c|c|c|c|c|}
\hline $\begin{array}{c}\text { Stage of renal } \\
\text { failure }\end{array}$ & $\begin{array}{c}\text { Normal serum } \\
\text { iron profile }\end{array}$ & Iron deficiency & $\begin{array}{c}\text { Acute phase } \\
\text { reaction }\end{array}$ & $\begin{array}{c}\text { Anemia of } \\
\text { chronic disease }\end{array}$ & Iron overload & Total \\
\hline Stage 3 & 2 & 0 & 2 & 0 & 0 & 4 \\
\hline Stage 4 & 11 & 1 & 3 & 0 & 0 & 15 \\
\hline Stage 5 & 22 & 0 & 46 & 5 & 2 & 75 \\
\hline Total & $\mathbf{3 5}$ & $\mathbf{1}$ & $\mathbf{5 1}$ & $\mathbf{5}$ & $\mathbf{2}$ & $\mathbf{9 4}$ \\
\hline
\end{tabular}

Table 4: Comparison of serum iron profile in CKD.

\begin{tabular}{|c|c|c|c|c|c|}
\hline Parameter & $\begin{array}{c}\text { Talwar et al } \\
\mathbf{2 0 0 2}^{\mathbf{1 0}}\end{array}$ & $\begin{array}{c}\text { Singh et al } \\
\mathbf{1 9 9 9}^{11}\end{array}$ & $\begin{array}{c}\text { Jairam et al } \\
\mathbf{2 0 1 0}^{\mathbf{1 2}}\end{array}$ & Deori Et al 2016 & Present study \\
\hline Serum iron $(\mu \mathrm{g} / \mathrm{dl})$ & 55.1 & $124.93 \pm 123.6$ & $153.4 \pm 31.6$ & $98 \pm 37.08$ & 61 \\
\hline TIBC $(\mu \mathrm{g} / \mathrm{dl})$ & - & - & $476.39 \pm 137.3$ & $345.22 \pm 75.43$ & 216.43 \\
\hline Serum ferritin $(\mathrm{ng} / \mathrm{dl})$ & 30.4 & $259.33 \pm 122.05$ & $331.7 \pm 39.56$ & - & 539.68 \\
\hline Transferrin saturation $(\%)$ & - & - & - & $30.78 \pm 14.45$ & $32.18 \%$ \\
\hline
\end{tabular}


phase reaction, this can be explained since the Deori et al selected the study population which did not receive any parenteral or oral hematinics. In contrast the present study selected the study population irrespective of their treatment status with hematinics or erythropoietin.

Chronic kidney disease is associated with systemic inflammation and oxidative stress due to activation of innate immune system directed by monocytes / macrophages, granulocytes and other non-immune cells ${ }^{15}$. Hence many of the patients in advanced stages of chronic kidney failure show acute inflammatory response with an increase in C-reactive proteins, hepcidin and serum ferritin. Due to chronic inflammatory state, patients may have functional iron deficiency and iron deficient erythropoiesis, even though marrow iron content is normal ${ }^{16}$. This scenario can be seen in our study population where $54.25 \%$ cases had serum iron profile suggestive of acute phase reaction.

In patients with kidney failure, presence of chronic inflammation over a long period of time can cause cytokine mediated inhibition of production of erythropoietin and premature destruction of precursor erythroblasts leading to hypo-proliferative anemia and anemia of chronic disease ${ }^{16}$.

Many of the patients in late stage CKD may receive erythropoietin and parenteral iron to prevent anemia and morbidities associated with anemia. This can lead to an iron overload in patients with functional iron deficiency.

Limitations of the study: (1) Inability to investigate full spectrum of iron status in CKD patients due to high cost of investigations and lack of funding. (2) The therapeutic status with erythropoietin and other drugs were not available for many of the patients.

\section{Conclusion}

Most common type of serum iron profile found in the study population was acute phase reaction (54\%) and majority of them were in stage 5 renal failure. As we understand by various studies that uremia is state of systemic inflammation and increase in serum ferritin and hepcidin can lead to functional iron deficiency. Parenteral iron therapy in these patients can lead to iron overload and toxic effects of iron overload. Hence, before beginning parenteral iron therapy, CKD patients should be screened for the presence of inflammation.

\section{Acknowledgements}

Dr Chethan Manohar, In Charge Hematology \& Clinical pathology lab for giving the permission to conduct the study

\section{Funding}

Not funded

\section{Competing Interests}

None

\section{References}

1. NKF-KDOQI clinical practice guidelines for chronic kidney disease: evaluation, classification and stratification. Part 4 and 5. Am.J.Kidney Dis (Suppl 1); 2002: 43-112.

2. Sargent JA, Acchiardo SR. Iron requirements in hemodialysis. Blood Purif. 2004; 22:112-123.

3. Wizemann V, Buddensiek P, de Boor J, et al. Gastrointestinal blood loss in patients undergoing maintenance dialysis. Kidney Int Suppl. 1983;16: S218-S220.

4. IC Macdougall et al.: Iron management in CKD: a KDIGO executive summary report.

5. Besarab A, Kaiser JW, Frinak S. A study of parenteral iron regimens in hemodialysis patients. Am J Kidney Dis. 1999; $34: 21-28$

6. Weiss $\mathrm{G}$ and Goodnough L, Anemia of Chronic Disease. N Engl J Med 2005; 352:1011- 1023.

7. Worwood M, May A. Iron deficiency anemia and iron overload. In: Dacie and Lewis practical hematology. 11th ed. Elsevier; Chrurchill livingstone. 2011;176- 196.

8. Van Bokhoven MA, van Deursen CT, Swinkels DW. Diagnosis and management of hereditary haemochromatosis. BMJ 2011;342:c7251.

9. Hershko C. Pathogenesis and management of iron toxicity in thalassemia. Ann N Y Acad Sci. 2010; 1202:1-9.

10. Worwood M, May A. Iron deficiency anemia and iron overload. In: Dacie and Lewis practical hematology. 11th ed. Elsevier; Chrurchill livingstone.2011. P. 176- 196.

11. Talwar VK, Gupta HL and Shashinarayan. Clinicohematological profile in chronic renal failure. JAPI. 2002; 50:228-233

12. Singh NP, Aggarwal L, Singh T, Anuradha S and kohli R. Anemia, Iron studies and erythropoietin in patients of chronic renal failure. JAPI.1999; 47(3):284-290

13. Jairam A et al. Iron status, inflammation and hepcidin in ESRD patients: the confounding role of intravenous iron therapy. Indian journal of nephrology. 2010; 20(3):125-131.

14. Deori $\mathrm{R}$ et al. Iron status in chronic kidney disease patients. International journal of research in medicine sciences. 2016; Aug; 8(4);3229-3234.

15. Vazir ND, Pahl MV, Crum A and Norris K. Effect of uremia on structure and function of immune system. J ren Nutr: 2012; 22(1): 149-156.

16. KDOQI clinical practice guidelines and clinical practice recommendations for anemia in chronic kidney disease. Am.J.Kidney Dis 2006 May;47(5):S28-32.

*Corresponding author:

Dr. Sushma Belurkar, Associate Professor and Clinical Lab In-Charge, Department of Pathology, Kasturba Medical college, Manipal Academy of Higher Education, Manipal, Karnataka, India.576104

Phone: +91 9448888415, Email: sushbelur@gmail.com

Date of Submission : 27/11/2019

Financial or other Competing Interests: None.

Date of Acceptance : 13/04/2020

Date of Publication : 27/06/2020 